\title{
ANALISIS SWOT GUNA MENINGKATKAN KESADARAN UMAT UNTUK MENYALURKAN ZAKAT MELALUI LEMBAGA AMIL ZAKAT DI BAZNAS KOTA BAUBAU
}

\author{
I Wayan Sujana*1 \\ ${ }^{1}$ Program Studi Akuntansi, Fakultas Ekonomi, Universitas Muhammadyah Buton, Baubau, Indonesia \\ e-mail: sujanawayan1@gmail.com
}

\begin{abstract}
ABSTRAK
Menurut undang-undang Nomor 23 Tahun 2011, fungsi BAZNAS yaitu melaksanakan perencanaan, pelaksanaan, pengendalian, pelaporan, pertanggungjawaban, pengumpulan, pendistribusian dan pendayagunaan zakat. Sejauh ini keberadaan organisasi pengelola zakat belum optimal diakibatkan masih banyak potensi zakat yang belum terkelola dengan baik. Tujuan dari penelitian ini adalah untuk mengetahui peran BAZNAS kota Baubau dalam meningkatkan kesadaran umat untuk menyalurkan zakatnya pada Lembaga Amil Zakat. Penelitian ini menggunakan metode analisis SWOT yakni membandingkan antara faktor eksternal, peluang, dan ancaman dengan faktor internal kekuatan dan kelemahan. Pengumpulan data dilakukan melalui wawancara. Melalui pendekatan analisis SWOT, skor faktor internal - kekuatan BAZNAS sebesar 2,66 dan skor faktor internal - kelemahan sebesar 0,68 dan jumlah keseluruhan dari faktor internal adalah 3,34. Hal tersebut berarti bahwa BAZNAS Kota Baubau mempunyai peran besar terhadap pendapatan BAZNAS. Skor faktor eksternal - peluang BAZNAS sebesar 2,40. Sedangkan skor faktor eksternal - ancaman sebesar 0,40 dan secara keseluruhan faktor eksternal mempunyai skor 2,80. Hal tersebut menggambarkan bahwa peluang BAZNAS sangat besar. Dari analisis skor tersebut dapat disimpulkan bahwa BAZNAS berada pada posisi kuadran I (positif) yang berarti bahwa lembaga ini kuat dan memiliki peluang. Strategi yang tepat digunakan oleh BAZNAS guna meningkatkan kesadaran muzakki yaitu strategi agresif berdasarkan kekuatan dan peluang pada BAZNAS kota Baubau antara lain berkoordinasi dengan semua Unit Pengumpul Zakat di setiap kecamatan di kota Baubau, meningkatkan sosialisasi kepada masyarakat, serta lebih meningkatkan pelayanan kepada masyarakat misalnya dengan memanfaatkan teknologi sehingga pengumpulan zakat dapat dilakukan melalui online dan akses masyarakat untuk melihat penyalurannya akan dapat dilakukan dengan baik.
\end{abstract}

\section{Kata Kunci: SWOT, Zakat, BAZNAS}

\begin{abstract}
According to Law Number 23 of 2011, the role of BAZNAS is to carry out the planning, execution, monitoring, reporting, accountability, collection, distribution, and utilization of zakat. So far the presence of zakat management organizations is not satisfactory due to the many potentials of zakat that have not been handled well. This study aimed to determine the role of BAZNAS in the city of Baubau in raising people's awareness of distributing their zakat to the Amil Zakat Institution. This study uses a method of SWOT analysis, which compares external factors, opportunities, and threats with the strengths and weaknesses of internal factors. The data was collected through interviews. Through the SWOT analysis approach, the internal factor score-the strength of BAZNAS is 2.66 and the internal factor score-the
\end{abstract}


weakness is 0.68 and the total internal factor score is 3.34. This means the City of Baubau's BAZNAS plays a significant role in BAZNAS income. External factor score - BAZNAS opportunities was 2.40. While the score of external factors - threats was 0.40 and overall external factors have a score of 2.80. This illustrates that the BAZNAS opportunity is very large. From the score analysis it can be concluded that BAZNAS is in the quadrant I position (positive) which means this institution is powerful and has opportunities. The right strategy used by BAZNAS to raise awareness of Muzakki is an aggressive strategy focused on strengths and opportunities in Baubau BAZNAS, among others, coordinating with all the Zakat collection units in each district of Baubau City, enhancing community socialization and further improving community services, for example, by using technology to allow zakat collection to be done well through online and public access.

Keywords: SWOT, Zakat, BAZNAS

\section{PENDAHULUAN}

Di Indonesia saat ini, pengkajian tentang ekonomi Islam selain tentang perbankan syariah juga tentang konsep dan pelaksanaan zakat, baik sebagai penunaian kewajiban pribadi yang merupakan suatu keharusan bagi umat Islam untuk saling menolong terhadap sesama maupun zakat sebagai bagian dari keuangan publik yang dikelola dan diberdayakan.

Undang-undang Nomor 23 Tahun 2011 mengenai pengelolaan zakat [1], memberikan model baru tentang tata cara mengelola zakat yang dilaksanakan oleh Badan Amil Zakat Nasional (BAZNAS). Pada dasarnya regulasi tersebut ada untuk menata perkembangan perzakatan di Indonesia. Lebih spesifik mengatur kedudukan serta fungsi BAZNAS secara kelembagaan. Kedudukan BAZNAS adalah lembaga nonstruktural independen yang bertanggungjawab kepada presiden melalui menteri. Sejumlah tugas koordinasi yang wajib diselenggarakan oleh BAZNAS yaitu perencanaan, pelaksanaan, pengendalian, pelaporan, pertanggungjawaban, pengumpulan, pendistribusian dan pendayagunaan zakat [2]. Kedudukan BAZNAS juga didukung oleh Keputusan Presiden Nomor 8 Tahun 2001. Selain BAZNAS lembaga yang bertanggung jawab dalam pengelolaan zakat adalah Lembaga Amil Zakat (LAZ). LAZ adalah suatu organisasi atau badan swasta yang berwenang untuk mengelola dana zakat, infaq dan sedekah [3].

Zakat adalah salah satu rangka pembinaan Islam. Tak dapat dipungkiri bahwa zakat merupakan salah satu rukun wajib (fardlu) dari rukun agama yang mengharuskan kita menyelenggarakannya [4]. Selain merupakan rukun wajib, zakat juga merupakan salah satu pilar 
kekuatan ekonomi Islam. Untuk meningkatkan kesadaran umat Islam dalam mengumpulkan zakat diperlukan sosialisasi yang intens agar umat lebih memiliki pengetahuan serta pemahaman tentang nilai, arti penting serta manfaat zakat. Hal ini pada akhirnya akan sangat berpengaruh terhadap kesadaran umat untuk mengumpulkan zakatnya dan dapat meningkatkan jumlah dana zakat [5].

Salah satu ide pokok tata kelola zakat yang tertuang dalam Undang-Undang Nomor 23 Tahun 2011 dan merupakan inti keseluruhan pasalnya adalah pengelolaan yang terintegrasi. Asas integrasi menjadi asas yang melandasi kegiatan pengelolaan zakat di Indonesia, baik yang dilakukan oleh BAZNAS maupun LAZ pada semua tingkatan yang sesuai dengan ketentuan perundang-undangan telah memperoleh legalitas [6].

Suatu hal yang menjadi problematika zakat adalah masih minimnya pengetahuan serta pemahaman umat Islam tentang zakat. ketidakmampuan menelusuri kebenaran ajaran Islam dalam berbagai perkara tak terkecuali zakat dapat menjerumuskan kita pada kezaliman. Bahkan, banyak umat Islam yang tidak mengetahui "disengaja" ataupun "tidak" tentang nisab dan haul. Sosialisasi tentang zakat pada masyarakat belum sepenuhnya mampu dilakukan oleh lembagalembaga konsultasi zakat. Sementara sistem ekonomi mengalami perkembangan setiap hari semakin bertambah dan bervariasi. Hal ini menuntut agar visi-misi tentang zakat juga harus dikembangkan sesuai dengan kebutuhan yang ada [7].

Dalam bidang sosial, zakat dapat menghilangkan sifat dengki dan benci kaum fakir dan miskin terhadap masyarakat sekitarnya. Dari segi ekonomi zakat mencegah terjadinya penumpukan kekayaan pada segelintir orang saja dan mewajibkan orang kaya untuk mendistribusikan harta kekayaannya pada orang miskin. Islam menjadikan instrumen zakat untuk memastikan keseimbangan pendapatan di masyarakat [8].

Zakat dalam ekonomi Islam adalah salah satu sistem keuangan yang berorientasi sosial sehingga pengelolaan zakat menjadi kajian penting dalam ekonomi Islam yaitu menjadi kajian keuangan sosial Islam (islamic social finance).

BAZNAS mempunyai peran yang sangat besar dalam mengoptimalkan pengelolaan zakat, sehingga akan mustahil terwujud tanpa adanya profesionalisme dalam manajemen pengelolaannya. Integrasi pengelolaan zakat menempatkan BAZNAS sebagai koordinator. dimana profesionalisme pengelolaan diwujudkan dengan prestasi terbaik, yakni dengan 
pengelolaan yang sehat dari seluruh aspek baik itu sumber daya manusia, perancangan, strategis, operasional dan keuangan [2].

Sejauh ini keberadaan organisasi pengelola zakat belum optimal diakibatkan masih banyak potensi zakat yang belum terkelola dengan baik. sehingga manfaatnya belum dapat dirasakan dalam meningkatkan kesejahteraan ekonomi umat sehingga perlu dilakukan analisis terkait strategi dalam perencanaan dan pengelolaannya baik terkait kekuatan, peluang, kelemahan dan ancaman atau analisis SWOT (Strenght, Opportunities, Weaknesses, Threaths). Analisis SWOT merupakan alat yang mampu menelaah berbagai faktor secara terstruktur untuk menguraikan strategi suatu organisasi maupun perusahaan. Analisis SWOT membandingkan antara faktor internal (kekuatan dan kelemahan) dan faktor eksternal (peluang dan ancaman) [9].

Penelitian terhadap BAZNAS telah banyak dilakukan, hasilnya antara lain: mengenai pandangan muzakki yang menyalurkan zakatnya melalui BAZNAS, temuan penelitian tersebut adalah pandangan muzakki yang menyalurkan zakatnya melalui BAZNAS lebih baik daripada yang disalurkan lewat nonlembaga [10]. Penelitian lain juga menemukan faktor pendorong terbesar yang memicu perubahan eksternal lembaga zakat adalah adanya kesadaran yang semakin meningkat dari wajib zakat (muzakki) serta adanya perubahan pengaturan dari pemerintah [11].

Masalah yang ada pada pengumpulan zakat adalah masih terdapat kesenjangan antara potensi zakat dan realisasi pengumpulan zakat. Berdasarkan hal tersebut tujuan dari penelitian ini adalah untuk mengetahui peran BAZNAS kota Baubau untuk meningkatkan kesadaran umat dalam menyalurkan zakatnya pada Lembaga Amil Zakat dan untuk melakukan analisis SWOT pada BAZNAS Kota Baubau guna meningkatkan kesadaran muzakki untuk menyalurkan zakatnya melalui Lembaga Amil Zakat.

\section{METODE PENELITIAN}

Jenis penelitian ini merupakan penelitian deskriptif analisis yang menggambarkan secara sistematis fakta yang ada di lapangan melalui kata atau kalimat serta aspek-aspek yang relevan dengan fenomena [12]. Jenis data pada penelitian ini adalah data primer dan data sekunder. Data primer adalah sumber data yang diperoleh secara langsung dari perusahaan atau organisasi [13]. Data primer pada penelitian ini diperoleh dengan mengadakan wawancara dengan Ketua 
BAZNAS Kota Baubau Bapak Sahirudin Udu secara langsung di lapangan. Data sekunder adalah data yang dikumpulkan melalui pihak kedua atau dari sumber-sumber lain yang telah tersedia sebelum penelitian dilakukan [14]. Penelitian ini menggunakan metode analisis SWOT yakni memadankan antara peluang dan ancaman sebagai faktor eksternal dengan kekuatan dan kelemahan sebagai faktor internal.

\section{HASIL DAN PEMBAHASAN}

Keberhasilan dalam mengelola suatu program memerlukan instrumen yang baik. Instrumen tersebut menjadi faktor yang paling berperan dalam menentukan keberhasilan kegiatan. Untuk menjalankan fungsinya secara maksimal, BAZNAS perlu didukung oleh kemampuan manajerial yang baik. Dalam pengelolaan zakat, profesionalisme merupakan hal penting. Hal ini disebabkan oleh adanya kecenderungan pengelolaan zakat yang sebatas ritual keagamaan, serta tidak memiliki dimensi sosial. Padahal, zakat disamping memiliki dimensi spiritual, juga berdimensi sosial.

Profesionalisme BAZNAS dapat diukur dengan tiga hal yaitu amanah. profesional, transparan. Amanah merupakan syarat mutlak yang harus dimiliki oleh setiap amil zakat yang merupakan jelmaan dalam sikap keras melawan korupsi, tegas melawan kecurangan dan menolak melakukan keburukan dan sejenisnya. Secara legal formal, zakat adalah dana umat (milik muzakki) yang dipercayakan kepada Organisasi Pengelola Zakat (OPZ) untuk dikelola.

Kemampuan Badan Amil Zakat (BAZ) dalam mengelola dana zakat membutuhkan sistem manajemen dengan perencanaan yang tepat. Perencanaan tersebut sangat dibutuhkan dalam setiap kegiatan organisasi guna mengetahui dan menentukan rencana maupun arah mengenai pengambilan keputusan (penempatan sumber daya termasuk manusia). Suatu BAZ yang memiliki perencanaan yang tepat akan dapat mengetahui gambaran atau perkiraan kondisi dimasa depan.

Potensi zakat di kota Baubau cukup besar, dan bisa mencapai nilai Rp.153,571 Milyar sementara yang terealisasi baru sekitar Rp.2,206,3 Milyar [15]. Ini disebabkan belum sentralisasinya pengumpulan zakat pada Lembaga Amil Zakat Kota baubau. Hal ini berdasarkan hasil wawancara bahwa sebagian besar muzakki dalam mengeluarkan zakatnya langsung kepada mustahik atau secara individu tidak melalui Lembaga Amil Zakat (LAZ). Berdasarkan hal 
tersebut sangat diperlukan langkah dan usaha dari organisasi pengelola zakat dalam hal ini BAZNAS kota Baubau untuk menumbuhkan dan meningkatkan kesadaran muzakki dalam menyalurkan zakatnya melalui organisasi atau badan pengelola zakat. Pada akhirnya muzakki menyadari bahwa dengan menyalurkan zakat melalui lembaga pengelola zakat maka jumlah zakat yang dikumpulkan akan sangat besar.

Untuk itu perlu peranan pemerintah kota Baubau baik terkait kebijakan dan sosialisasi dalam meningkatkan kesadaran masyarakat (umat Islam) dalam hal ini muzakki untuk mengumpulkan zakatnya melalui LAZ. Adapun kebijakan yang dapat dilakukan yaitu melakukan seminar-seminar serta sosialisasi melalui media online ataupun cetak, membuat peraturan daerah terkait pengelolaan zakat, sosialisasi melalui majelis taklim, khutbah jumat, serta memaksimalkan kerja Unit Pengelola Zakat (UPZ) di tiap-tiap kecamatan.

Tinjauan analisis SWOT yang dilakukan sebagai upaya meningkatkan kesadaran muzakki dalam mengumpulkan zakatnya melalui BAZNAS Kota Baubau dengan melihat kekuatan serta peluang yang ada dan dapat dimanfaatkan dengan baik. Selain itu untuk mengetahui kelemahan guna mengatasi ancaman yang akan terjadi. Berikut analisis SWOT (Strenght, Weakness, Opportunities, Threat) BAZNAS kota Baubau:

a. Strenght (S)

1) Memiliki badan hukum

2) Memiliki infrastruktur berupa gedung kantor BAZNAS

3) Mempunyai struktur organisasi dan wewenang yang jelas dan legal

4) Rapat dan sosialisasi serta pembinaan

5) Bersifat independen, netral

6) Menyalurkan zakat secara terprogram dan bertanggung jawab

7) Pendistribusian zakat dilakukan secara adil

b. Weakness (W)

1) Sumber daya manusia yang masih kurang maksimal

2) Masih kurangnya keterampilan manajemen

3) Akuntabilitas pengelolaan zakat belum bisa di akses oleh masyarakat

4) Kurang inovatif dan kreatif 
5) Belum mempunyai visi pemberdayaan

6) Pendayagunaan zakat masih bersifat konsumtif

7) Masih banyak masyarakat yang belum mengetahui tentang BAZNAS

8) Lokasi BAZNAS kurang strategis

\section{c. Opportunities (O)}

1) Masyarakat kota Baubau mayoritas beragama Islam

2) Potensi muzakki sangat besar

3) Sebagian masyarakat percaya bahwa BAZNAS kota Baubau dikelola secara professional

\section{d. Threat $(\mathrm{T})$}

1) Kurangnya pemahaman masyarakat tentang zakat dan sistem syariah

2) Masih banyak masyarakat yang menyalurkan zakatnya langsung secara pribadi kepada mustahik.

3) Kurangnya kesadaran masyarakat untuk mengumpulkan zakatnya melalui Lembaga Amil Zakat.

Dari hasil analisis SWOT pada BAZNAS diatas diidentifikasi menggunakan analisis IFAS dan EFAS maka hasil analisis strateginya adalah sebagai berikut:

a. Strategi SO (Strength-Opportunities)

Dengan kejelasan BAZNAS memiliki badan hukum maka masyarakat kota Baubau yang mayoritas beragama Islam untuk tidak ragu menyalurkan zakatnya pada lembaga ini. Disamping itu, potensi muzakki yang sangat besar akan memberikan dampak pada tersalurkannya zakat bagi mustahik. Adanya infrastruktur berupa gedung BAZNAS maka akan memudahkan muzakki untuk mengumpulkan zakatnya langsung pada lembaga ini. Sebagai lembaga yang bersifat independen dan netral maka BAZNAS tidak akan memihak pada siapapun, sehingga penyaluran dana zakat akan lebih adil. Adanya sosialisasi tentang zakat akan memberikan pengetahuan pada masyarakat tentang zakat, mulai dari pengumpulan, perhitungan, pendistribuasian dan pendayagunaannya. Dengan dikelolanya dana zakat secara terprogram dan bertanggung jawab maka masyarakat percaya bahwa 
BAZNAS Kota Baubau dikelola secara professional.

\section{b. Strategi ST (Strength-Threats)}

Dengan adanya sosialisasi dan pembinaan maka akan memberikan pemahaman kepada masyarakat tentang pengelolaan zakat dan sistem syariah. Melalui sosialisasi masyarakat akan mengetahui dan memahami bahwa BAZNAS merupakan lembaga yang mempunyai badan hukum untuk pengumpulan, penyaluran, pendistribusian dan pendayagunaan zakat yang dikumpulkan dari masyarakat atau muzakki. Pada akhirnya, masyarakat atau muzakki tidak lagi menyalurkan zakatnya secara langsung kepada mustahik.

\section{c. Strategi WO (Weaknesses-Opportunities)}

Memberikan sosialisasi dan pelatihan kepada sumber daya manusia BAZNAS sehingga pemahaman pengelola akan bertambah dan harus dilakukan secara berkelanjutan, menyediakan pengelola yang kompeten, memiliki pengetahuan dan pengalaman terkait pengelolaan zakat, agar masyarakat memercayai bahwa BAZNAS di kelola secara professional. Hal ini dapat didukung dengan akuntabilitas pengelolaan zakat harus dapat diakses oleh masyarakat secara luas melalui teknologi, sehingga diperlukan pengelola yang menguasai teknologi untuk penyajian laporan pertanggungjawaban.

Selain itu dengan banyaknya masyarakat kota Baubau yang beragama Islam dan potensi muzakki yang sangat besar maka visi pemberdayaan oleh BAZNAS dalam hal penyaluran seharusnya tidak hanya bersifat konsumtif tetapi juga produktif dengan menciptakan inovasi dan kreasi melalui ide-ide kreatif misalnya pembiayaan, mengembangkan produk baru dan sebagainya.

\section{d. Strategi WT (Weaknesses-Threats)}

Sosialisasi dan pelatihan dilakukan untuk menambah kemampuan dan pengetahuan pengelola agar lebih terarah dan tertata dengan baik. Pendayagunaan zakat yang hanya bersifat konsumtif dapat dikembangkan melalui pendayagunaan yang bersifat produktif yakni melakukan inovasi serta kreatif dalam mengembangkan produk atau usaha baru untuk meningkatkan kesejahteraan masyarakat tidak mampu atau mustahik. Dengan harapan mustahik yang telah produktif nantinya akan berubah menjadi muzakki. Nantinya, 
muzakki akan terpanggil untuk menyalurkan zakatnya melalui badan amil zakat karena percaya bahwa BAZNAS mengelola dana zakat secara professional, akuntabel dan bertanggung jawab.

Tabel 1. Matriks IFAS

\begin{tabular}{|c|c|c|c|c|}
\hline \multicolumn{2}{|c|}{ Faktor Internal } & Bobot & Rating & Skor \\
\hline \multicolumn{5}{|c|}{ Kekuatan } \\
\hline & Memiliki Badan Hukum & 0.15 & 4 & 0.60 \\
\hline 2 & Memiliki Infrastruktur berupa gedung kantor BAZNAS & 0.08 & 4 & 0.32 \\
\hline 3 & Mempunyai struktur organisasi dan wewenang yang jelas dan legal & 0.08 & 3 & 0.24 \\
\hline 4 & Rapat dan Sosialisasi serta pembinaan & 0.10 & 4 & 0.40 \\
\hline 5 & Bersifat independen, netral & 0.10 & 3 & 0.30 \\
\hline 6 & Menyalurkan zakat secara terprogram dan bertanggung jawab & 0.10 & 4 & 0.40 \\
\hline & Pendistribusian zakat dilakukan secara adil & 0.10 & 4 & 0.40 \\
\hline \multicolumn{2}{|c|}{ Total Kekuatan } & 0.71 & & 2.66 \\
\hline \multicolumn{5}{|c|}{ Kelemahan } \\
\hline 1 & Sumber daya manusia yang masih kurang maksimal & 0.04 & 3 & 0.12 \\
\hline 2 & Masih kurangnya keterampilan manajemen & 0.04 & 2 & 0.08 \\
\hline 3 & Akuntabilitas pengelolaan zakat belum bisa di akses oleh masyarakat & 0.04 & 2 & 0.08 \\
\hline 4 & Kurang inovatif dan kreatif & 0.03 & 3 & 0.09 \\
\hline 5 & Belum mempunyai visi pemberdayaan & 0.03 & 2 & 0.06 \\
\hline 6 & Pendayagunaan zakat masih bersifat konsumtif & 0.04 & 2 & 0.08 \\
\hline 7 & Masih banyak masyarakat yang belum mengetahui tentang BAZNAS & 0.04 & 2 & 0.08 \\
\hline & Lokasi BAZNAS kurang strategis & 0.03 & 3 & 0.09 \\
\hline \multicolumn{2}{|c|}{ Total Kelemahan } & 0.29 & & 0.68 \\
\hline \multicolumn{2}{|c|}{ Total } & 1.00 & & 3.34 \\
\hline
\end{tabular}

Sumber: Data Diolah 2020

Tabel 1 dapat dilihat faktor internal yakni kekuatan mempunyai skor 2,66 dan skor kelemahan 0,68 dan jumlah keseluruhan dari faktor internal adalah 3,34. Hal tersebut berarti bahwa BAZNAS Kota Baubau mempunyai peran besar terhadap pendapatan BAZNAS. 
Tabel 2. Matriks EFAS

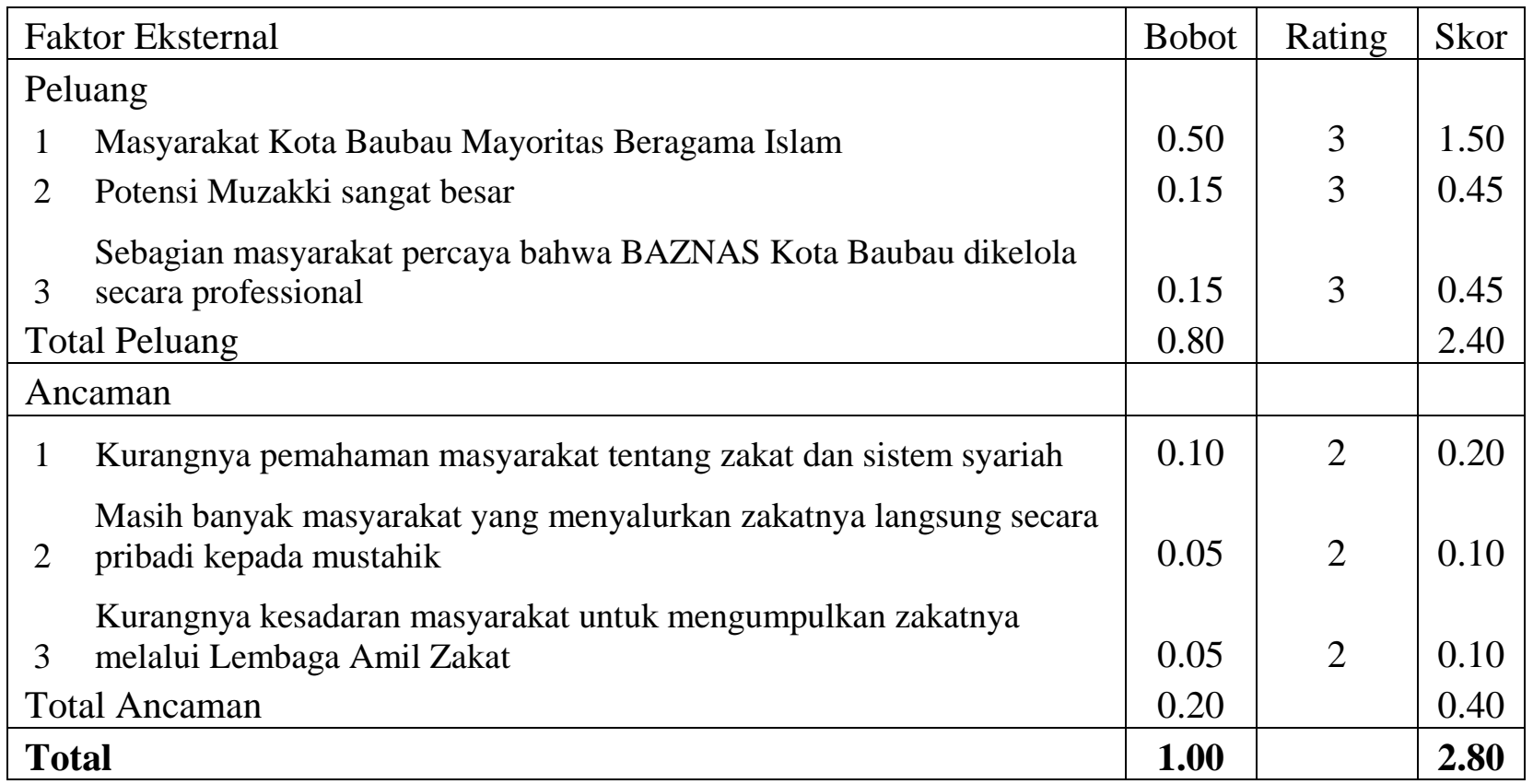

Sumber: Data Diolah 2020

Tabel 2 dapat dilihat BAZNAS mempunyai peluang yang besar yakni 2,40. Sedangkan ancaman 0,40 dan secara keseluruhan faktor eksternal mempunyai skor 2,80. Hal tersebut menggambarkan bahwa peluang BAZNAS sangat besar.

Berdasarkan hasil analisis lingkungan eksternal dan internal yang diidentifikasi menggunakan analisis IFAS dan EFAS menghasilkan masing-masing skor. Melalui pendekatan analisis SWOT dapat disimpulkan BAZNAS berada pada posisi kuadran I (positif) yang berarti bahwa lembaga ini kuat dan memiliki peluang sehingga strategi yang tepat untuk direkomendasikan adalah strategi ofensif yaitu menggunakan semua kekuatan untuk mengambil atau memanfaatkan peluang yang ada. Selain itu, strategi yang tepat digunakan oleh BAZNAS guna meningkatkan kesadaran muzakki untuk menyalurkan zakatnya pada LAZ yakni strategi agresif berdasarkan kekuatan dan peluang pada BAZNAS kota Baubau antara lain berkoordinasi dengan semua UPZ di setiap kecamatan di kota Baubau, meningkatkan sosialisasi kepada masyarakat, serta lebih meningkatkan pelayanan kepada masyarakat misalnya dengan memanfaatkan teknologi sehingga pengumpulan zakat dapat dilakukan melalui online dan akses masyarakat untuk melihat penyalurannya akan dapat dilakukan dengan baik. 


\section{KESIMPULAN}

Berdasarkan hasil penelitian dan pembahasan maka kesimpulan penelitian ini adalah peran BAZNAS dalam upaya menumbuhkan kesadaran agar muzakki menyalurkan zakatnya melalui Badan Amil Zakat (BAZ) adalah mengadakan sosialisasi serta pelatihan guna memberikan pemahaman pada masyarakat bagaimana seharusnya mengumpulkan, menyalurkan, mendistribusikan, mendayagunakan zakat oleh muzakki kepada mustahik. Hal ini dapat dilakukan melalui media online ataupun cetak. Mengadakan rapat dengan instansi Pemerintah daerah dan UPZ setiap kecamatan. BAZNAS berada pada posisi kuadran I (positif) yang berarti bahwa lembaga ini kuat dan memiliki peluang sehingga strategi yang tepat untuk direkomendasikan adalah strategi ofensif yaitu menggunakan semua kekuatan untuk mengambil atau menanfaatkan peluang yang ada. Selain itu, strategi yang tepat digunakan oleh BAZNAS guna meningkatkan kesadaran muzakki untuk menyalurkan zakatnya pada LAZ yakni strategi agresif berdasarkan kekuatan dan peluang pada BAZNAS kota Baubau antara lain berkoordinasi dengan semua UPZ di setiap kecamatan di kota Baubau, meningkatkan sosialisasi kepada masyarakat, serta lebih meningkatkan pelayanan kepada masyarakat misalnya dengan memanfaatkan teknologi sehingga pengumpulan zakat dapat dilakukan melalui online dan akses masyarakat untuk melihat penyalurannya akan dapat dilakukan dengan baik.

\section{SARAN}

Saran dari peneliti yaitu, sebaiknya pemerintah atau BAZNAS perlu menyediakan akses bagi masyarakat agar dapat melihat atau menganalisis pengelolaan zakat di Kota Baubau melalui media online atau media cetak. Selain itu, lokasi kantor BAZNAS sebaiknya di posisi strategis agar muzakki tidak kesulitan menemukan lokasinya. Penyaluran zakat yang bersifat konsumtif agar dikembangkan ke penyaluran yang sifatnya produktif.

\section{DAFTAR PUSTAKA}

[1] Undang-Undang Republik Indonesia No. 23 Tahun 2011 tentang Pengelolaan Zakat

[2] Sri Nurhayati, dkk. 2019. Akuntansi dan Manajemen Zakat. Jakarta: Salemba Empat

[3] Bank Indonesia. 2016. Pengelolaan Zakat Yang Efektif: Konsep dan Praktik di Beberapa Negara. Departemen Ekonomi dan Keuangan Syariah -P2EI-FE UII. di 
akses tanggal 25 Maret 2020, dari https://www.bi.go.id/id/publikasi/seri-ekonomikeuangan-syariah/Pages/Buku-Pengelolaan-Zakat.aspx.

[4] Hasbi Ash Shiddieqy. 2012. Pedoman Zakat. Cetakan Kedua Edisi Ketiga. Semarang: Pustaka Rizki Putra

[5] Samdin. 2015. Teori Motivasi Berzakat: Kajian Manfaat Ekonomi, Sosial, dan Dorongan Kelembagaan. Kendari: SS-DZ Grafika.

[6] Nazar, M. Fuad. 2011. Pengelolaan Zakat Dalam Undang-Undang No.23 Tahun 2011. diakses pada tanggal 8 Januari 2020 dari http://baznas.ciamiskab.go.id,

[7] Akhmad Mujahidin. 2014. Ekonomi Islam: Sejarah, Konsep, Instrumen, Negara, dan Pasar. Edisi Revisi. Jakarta: Rajawali Pers.

[8] Rozalinda. 2016. Ekonomi Islam: Teori dan Aplikasinya pada Aktivitas Ekonomi, Edisi 1, Cetakan 3. Jakarta: Rajawali Pers.

[9] Freddy Rangkuti. 2013. Analisis SWOT Tekhnik Membedah Kasus Bisnis, Jakarta: Gramedia Pustaka Utama.

[10] Shalihati, F. 2010. Analisis Persepsi dan Sikap Muzakki terhadap Badan Amil Zakat Nasional di Kota Jakarta. Tesis. Bogor MB.IPB

[11] Rukmana. 2014. Formulasi Strategi Transformasi pada Lembaga Amil Zakat Nasional Dompet Dhuafa. Tesis. Bogor. MB.IPB

[12] Sekaran, U. \& R. Bougie. 2010. Research Methods for Business : A Skill Building Approach, United Kingdom : John Wiley \& Sons Ltd.

[13] Sugiyono. 2017. Metode Penelitian Kuantitatif, Kualitatif, dan $R \& D$. Bandung: Alfabeta.

[14] Silalahi, U. 2012. Metode Penelitian Sosial. Bandung: Reflika Aditama.

[15] BAZNAS Kota Baubau. 2017. Laporan Penerimaan Zakat Maal, Zakat Fitrah, dan Infaq/ Sadaqah. 